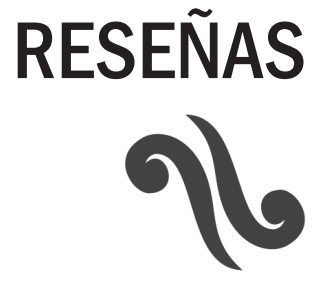





\title{
Movimientos sociales en el siglo XXI ${ }^{*}$
}

\author{
Carlos Rafael Rea Rodríguez
}

En momentos en que el mundo social se transforma de manera radical, emerge con fuerza la necesidad de repensar las teorías y las herramientas metodológicas con las cuales hemos intentado entenderlo hasta entonces, para poder incidir en él de forma pertinente. En los años que corren, vivimos transformaciones de esa envergadura. En los albores del nuevo siglo, muchas de las dinámicas e instituciones que la modernidad capitalista occidental nos legó, han entrado en grave crisis, lo mismo que su más reciente expresión neoliberal, dejando como saldo, pobreza y desigualdad extremas, depredación acelerada de la naturaleza, debilitamiento agudo de la institucionalidad política, desdibujamiento de los horizontes ideológico-políticos otrora vigentes, precarización creciente de la vida social, económica y cultural.

En ese complejo escenario, el destino individual y colectivo se enfrenta ante profundos desafíos para ser pensado, vivido, imaginado y reinventado creativamente. La problemática construcción de las sociedades y la conformación de los actores sociales, se desarrollan en un delgado sendero que a los extremos encuentra, por un lado, las fuerzas del mercado, que en el límite despersonalizan y deshumanizan con la masificación y la necesidad ilimitada de consumo que inocula, y en el otro, el comunitarismo esencialista y cerrado, que subyuga hasta borrarlas, las voluntades y proyectos de vida personales. En un contexto de debilitamiento del tejido social, de retracción de categorías sociopolíticas aglutinadoras y de proliferación de los particularismos culturales, transita la difícil y nunca plenamente realizada construcción de los sujetos individuales y colectivos. Ese precario trabajo sobre sí mismo, se expresa en resistencias y voluntad de autonomía, persiguiendo y forjando dicha construcción al lado de otros empeñados en la misma búsqueda, que es al mismo tiempo individual y

\footnotetext{
* Reseña de la obra de Geoffrey Pleyers, Movimientos sociales en el siglo XXI. Perspectivas y herramientas analiticas, Buenos Aires: Clacso, 2018.
} 
colectiva, y que constituye la condición de posibilidad para participar activamente de la vida económica y la vida comunitaria sin ser borrado por ellas.

Evidentemente, la teoría social y, en particular, las teorías sobre los movimientos sociales, se encuentran igualmente sumergidas en esa tendencia de cambio, de la cual deben salir sustancialmente modificadas. Esta obra que reseńamos ahora, se sitúa precisamente en una tesitura reflexiva, crítica y autocrítica, que permite reflexionar y proponer nuevos caminos. En ese sentido, constituye un valioso aporte para el estudio contemporáneo de los movimientos sociales, así como para pensar en diversos sentidos el mundo actual.

En un periodo en el que la literatura académica sobre el tema de los movimientos sociales está hegemonizada en el contexto internacional por la perspectiva centrada en la racionalidad estratégica de los actores sociales, en su manifestación colectiva a partir de eventos disruptivos y en el impacto de sus prácticas sobre las instituciones políticas (la protesta social y la política de lo contencioso), aparece esta aguda obra que no se deja atrapar por viejas o nuevas dicotomías analíticas y que, en cambio, propone al lector una perspectiva multidimensional que rescata aportes teóricos y metodológicos de distintos orígenes, filtrados por el tamiz de un nutrido análisis empírico. Sin renunciar a los aportes de la sociología europea y anglosajona, la reflexión que Pleyers nos ofrece, apuesta por recuperar las epistemologías del sur, superando tanto visiones teóricas globalistas como nacionalistas y proponiendo en cambio, un trabajo sociológico multisituado y multiescalar, que se nutra lo mismo de la experiencia empírica local y cotidiana de los actores, que de las discusiones teóricas sobre lo social al nivel más general.

La obra, que va acompañada de un prefacio y un postfacio, consta de una introducción y trece capítulos, organizados en cuatro apartados. El primer apartado del libro está compuesto por cinco capítulos. El primero de ellos dedicado a los movimientos sociales en la década de 2010. En estos movimientos se articulan, de forma distinta a como sucedía en el periodo en que predominaban los denominados nuevos movimientos sociales, las demandas en torno a cuestiones tanto culturales como socioeconómicas. Igualmente, hacen un uso intensivo de las tecnologías de la información y las redes digitales, las cuales desempeñan un papel que, si bien no sustituye al activismo en las calles, sí lo complementa y lo potencia, contribuyendo incluso a la transformación de las subjetividades. De la misma manera, reflexiona sobre el significado que tiene la democracia para este tipo de militantes, la cual se convierte al mismo tiempo en una forma de experiencia y de experimentación, que coloca como central la relación consigo mismo y con la producción de su propia subjetividad, como premisas para generar nuevas formas de sociabilidad.

El segundo capítulo aborda las que el autor identifica como las dos vías del activismo de finales del siglo XXI: la vía de la razón y la vía de la subjetividad. La primera es entendida como el cuestionamiento de la ideología neoliberal, con 
el respaldo del discurso científico-técnico producido o esgrimido por actores de la sociedad civil institucionalizada, en el esfuerzo por construir una ciudadanía más participativa y sociedades más democráticas. La segunda, en cambio, prioriza la reivindicación personal y colectiva de la autonomía, la experiencia, la subjetividad y la creatividad, así como el carácter performativo y prefigurativo de los movimientos sociales, los cuales aspiran a la transformación del mundo aquí y ahora y de abajo hacia arriba, asumiendo a plenitud la significación global de sus luchas.

El capítulo tercero establece que el alteractivismo coloca la experiencia propia en el centro de la militancia, en su doble acepción de experiencia vivida y experimentación, por lo cual resulta tan importante enfrentar al adversario como luchar contra uno mismo, en el camino de producir desde la misma vida cotidiana, espacios autónomos, liberados del neoliberalismo y el capitalismo, del poder y la ganancia. De manera destacada, el autor advierte sobre el riesgo que corre esta forma de activismo si dedica demasiada atención y energías a la experiencia propia, dejando de lado el conflicto contra los adversarios sociales, lo cual redundaría en incapacidad para provocar transformaciones estructurales en la sociedad o en la despolitización del significado de su acción.

El capítulo cuarto plantea la relación entre activismo e internet en el siglo XXI, advirtiendo de no caer en la tentación de sobrevaluar el rol de las tecnologías y aseverando que es la vinculación dinámica entre el activismo en las redes y el activismo en las calles lo que verdaderamente potencia su impacto político y la transformación de las subjetividades y el tejido social. En la batalla por la información, los medios digitales, más que sustituir a los medios tradicionales y al activismo en las calles y plazas, se combinan con ellos, articulando dinámicas virtuales y vida militante, vida cotidiana y lucha política.

En el quinto capítulo, Pleyers plantea que los movimientos sociales aún desempeñan un papel central como productores de la sociedad. Sin embargo, para comprender mejor su potencial transformador, es preciso superar los sesgos epistémicos de los enfoques actualmente predominantes, los cuales se concentran en los impactos institucionales y de corto plazo de los mismos, dejando de lado la incidencia sobre las subjetividades, las formas de socialización y sociabilidad, y en la conformación de horizontes de experiencia democrática, a la vez espirituales y utópicos, con un potencial social a la vez performativo y prefigurativo. De la misma forma, es preciso asumir que también existen movimientos elitistas, conservadores y reaccionarios, los cuales actúan, junto con actores políticos e instituciones hegemónicas, para asegurar la reproducción de la dominación sistémica global.

El segundo apartado del texto está compuesto por tres capítulos. El capítulo sexto reflexiona sobre las posibilidades de que la acción social se internacionalice sin que necesariamente tenga que institucionalizarse y burocratizarse. $\mathrm{Al}$ analizar 


\section{C.R. REA RODRÍGUEZ MOVIMIENTOS SOCIALES EN EL SIGLO XXI}

la dinámica de las redes internacionales que forman parte del Foro Social Mundial durante una década, observa que la mencionada tendencia a la institucionalización es muy fuerte y que, sin embargo, es perfectamente posible reconocer una mayor participación de los activistas de movimientos de base bajo formatos más horizontales. Éstos han demostrado que son capaces de conformar redes al mismo tiempo diversas, democráticas, fluidas y eficientes, evitando ceder al predominio de las organizaciones no gubernamentales altamente profesionalizadas que propician la elitización y burocratización.

En el capítulo séptimo se propone que para pensar en una sociología global en el periodo actual, es necesario articular la reflexión microsociológica y el estudio de las teorías generales de la sociedad, vincular en la investigación la dimensión empírica y teórica, así como desarrollar una investigación multisituada, multiescalar, que asuma el diálogo intercultural, como vía para superar el nacionalismo y el globalismo metodológico. De la misma forma, debe reconocerse a los actores sociales como productores de prácticas, conocimientos y visiones del mundo, que luchan simultáneamente contra el capitalismo neoliberal y por producir otro tipo de subjetividades y de vínculo social, a partir de la relación fundamental con el territorio local, desde donde se interconectan con lo global a partir de los significados de su acción.

El tercer apartado, que consta de tres capítulos, aborda la experiencia reciente de lucha social en América Latina y particularmente en México. En el capítulo octavo, Pleyers identifica cuatro frentes de una lucha que es común en América Latina, la lucha "por una verdadera democracia": en primer lugar, nos habla de la lucha protagonizada por movimientos indígenas y campesinos en defensa de la tierra, el territorio y la naturaleza; en segundo, de los movimientos por la democratización, que canalizan muchas de sus energías a la "democratización de los medios de comunicación” y a denunciar la colusión entre grandes capitales, élites políticas y grandes medios de comunicación; en tercer lugar, de las luchas en defensa de la educación y, finalmente, de los movimientos por la paz y la justicia.

El capítulo noveno está dedicado al análisis de la violencia en México, contrastando dos modelos de políticas en la materia: una que apuesta a la militarización, que fue la impuesta desde el gobierno de Felipe Calderón, y otra centrada en la seguridad humana, que implica una participación relevante de la sociedad civil. Para Pleyers, en México han confluido una baja regulación estatal, el debilitamiento de instituciones y del vínculo social, al igual que la presencia de altos niveles de corrupción e impunidad, factores que han abonado a la instalación de un agudo clima de violencia. En ese contexto, se conformó el Movimiento por la Paz con Justicia y Dignidad, movimiento que permitió "liberar la palabra" de los familiares de las personas desaparecidas, poniendo en el centro de su lucha, la experiencia vivida, las emociones, la subjetividad y la compasión. 
El capítulo décimo analiza algunos de los principales movimientos sociales en México durante la década reciente, entre los que destacan las movilizaciones en defensa del territorio, la autonomía y la dignidad, los cuales al tiempo que resisten y se oponen al neoextractivismo capitalista, forjan alternativas de vida desde el ámbito local y la vida cotidiana. No obstante, estos movimientos enfrentan el difícil desafío de producir articulaciones a escala estatal y nacional, capaces de producir transformaciones estructurales mayores.

El último apartado constituye un personal homenaje del autor a dos de sus grandes referencias teóricas: Alain Touraine y François Houtart. Así, el capítulo décimo primero trata sobre el itinerario biográfico e intelectual de Alain Touraine, y su recorrido por los grandes temas del movimiento obrero, los nuevos movimientos sociales, la autoproducción de la sociedad, la democracia, el sujeto personal y colectivo, enfatizando que para el sociólogo francés, el papel del sociólogo es identificar detrás del discurso de los actores, el significado de sus acciones y los conflictos sociales que protagonizan.

El último capítulo está dedicado a la vida y obra de François Houtart, autor que impulsó el rol emancipador de la iglesia en el mundo, desde el diálogo entre iglesias y la opción preferencial por los pobres. Houtart esgrimía que contra la mundialización neoliberal, había que enarbolar "la mundialización de las resistencias y las luchas" en la defensa de los bienes comunes de la humanidad y la ecología, así como "la mundialización de la justicia, el amor y la vida" para hacer posible la emancipación y la creación de un mundo post-capitalista.

Geoffrey Pleyers lanza entre líneas en el libro, dos consideraciones que son de suma importancia: 1) cuando los movimientos sociales se vuelcan sobre sí mismos y su experiencia, muy probablemente estarán cancelando la posibilidad de incidir en la transformación estructural y general de la sociedad, de ahí la trascendencia sociopolítica de la interseccionalidad y la articulación multiescalar de las luchas $y, 2)$ la preocupación por la descolonización del pensamiento, llevada al extremo, puede conducir al desconocimiento de los aportes y reflexiones que desde el norte global la academia socialmente comprometida y los propios movimientos sociales generan continuamente. Por eso la importancia de sostener en el trabajo sociológico, no sólo un permanente y polifónico diálogo sur-sur, sino también un diálogo sur-norte, que supone investigar y formular desde nuestro propio lugar de observación y enunciación, reflexiones sobre lo que sucede en los países del norte global. En síntesis, en esta obra Geoffrey Pleyers nos invita a asumir el desafío de construir la teoría social y la teoría sobre los movimientos sociales desde una actitud dialógica, intercultural, multisituada y multiescalar, abierta al carácter glocal de los movimientos sociales contemporáneos. 



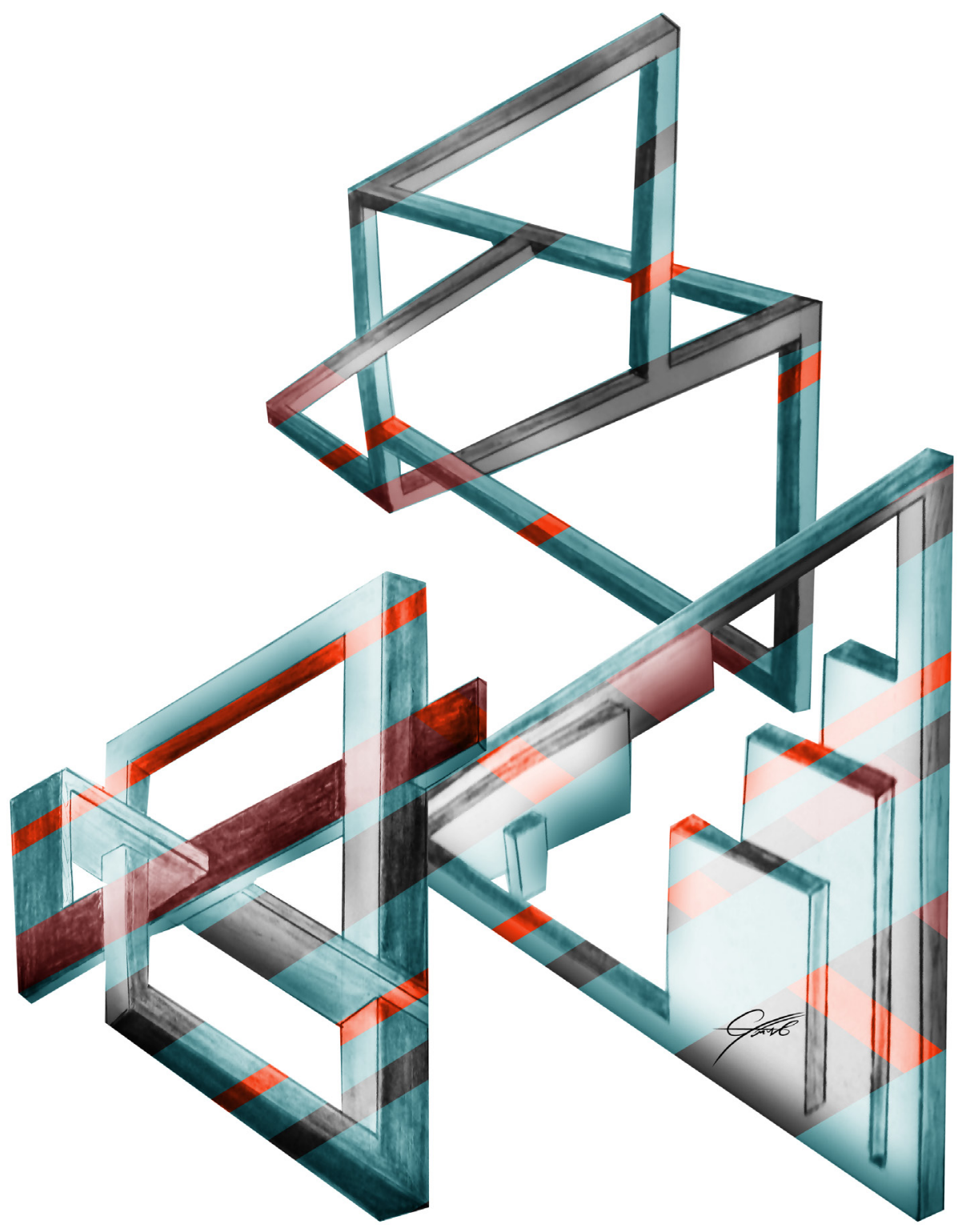


Alejandro Casales Navarrete $\mid$ Forma $X$ 